\title{
Desenvolvimento profissional docente e formação do sujeito criativo investigativo de acordo com a Base nacional comum curricular para o ensino de ciências*
}

Carlos José Trindade da Rocha'

\section{RESUMO}

O texto apresentou um estudo sobre o desenvolvimento profissional docente, no qual professores podem desenvolver criatividade e autonomia formativas, em particular para o ensino por investigação. Visou-se ainda propor a formação do sujeito criativo investigativo, alinhada à nova Base Nacional Comum Curricular. Dentro de uma abordagem qualitativa associou-se a proposta a um plano de trabalho de estágio pós-doutoral em uma universidade pública do Amazonas. A proposta permite efetivar o desenvolvimento profissional docente em perspectiva de modalidades de ações investigativas, apresentando condução de atos criativos no contexto educativo. Os elementos das relações de fases de criatividade e modalidades de ações investigativas podem ser considerados para a efetiva concretização dos pressupostos de formação do sujeito criativo investigativo e podem ser transferidos para diversos atos de ensino direcionado à educação científica.

\section{PALAVRAS-CHAVE}

formação de professores; criatividade; ensino por investigação; Base Nacional Comum Curricular.

\footnotetext{
'Secretaria de Estado de Educação do Pará, Belém, PA, Brasil.

*Texto produzido com base no plano de trabalho realizado com financiamento da Coordenação de Aperfeiçoamento de Pessoal de Nível Superior - Brasil (CAPES) - Edital 029/2019, no âmbito de estágio pós-doutoral do Programa de Pós-Graduação em Ensino de Ciências e Matemática da Universidade Federal do Amazonas (PPGECIM/UFAM), Programa de Cooperação Acadêmica (PROCAD) do CAPES.
} 
TEACHER PROFESSIONAL DEVELOPMENT AND

TRAINING OF THE CREATIVE INVESTIGATIVE

SUBJECT BASED ON THE BRAZILIAN COMMON

CURRICULAR BASE FOR SCIENCE TEACHING

\begin{abstract}
The text presented a study on teacher professional development, in which teachers can develop formative creativity and autonomy, mainly for teaching by inquiry. It was also aimed at proposing the formation of the investigative creative subject, in line with the new Brazilian Common Curricular Base (Base Nacional Comum Curricular). Within a qualitative approach, the proposal was associated with a post-doctoral internship work plan at a public university in Amazonas. The proposal allows to effectuate teacher professional development in terms of investigative action modalities, presenting the conduction of creative acts in the educational context. The elements of relations between phases of creativity and modalities of investigative actions can be considered for the effective realization of the formation presuppositions of the investigative creative subject and can be transferred to several teaching acts towards scientific education.
\end{abstract}

\title{
KEYWORDS
}

teacher training; creativity; teaching by inquiry; Brazilian Common Curricular Base.

\section{DESARROLLO PROFESIONAL DE DOCENTES Y FORMACIÓN DEL SUJETO CREATIVO INVESTIGATIVO BASADO EN LA BASE CURRICULAR COMÚN BRASILEÑA PARA LA ENSEÑANZA DE LA CIENCIA}

\section{RESUMEN}

El texto presentó un estudio sobre el desarrollo profesional de docentes en el que los profesores pueden desarrollar la suya creatividad y autonomía formativa, en particular para la enseñanza por investigación. También se buscó proponer la formación del sujeto creativo de investigación, en línea con la nueva Base Curricular Común Brasileña. Dentro de un enfoque cualitativo, la propuesta se asoció con un plan de trabajo de pasantía posdoctoral en una universidad pública en Amazonas. La propuesta permite la realización del desarrollo profesional de docentes en términos de modalidades de acción de investigación, presentando la realización de actos creativos en el contexto educativo. Los elementos de las relaciones entre las fases de la creatividad y las modalidades de las acciones de investigación pueden considerarse para la realización efectiva de las presuposiciones de formación del sujeto creativo de investigación y transferirse a varios actos de enseñanza direccionados para la educación científica.

PALABRAS CLAVE

formación de profesores; creatividad; enseñanza por investigación; Base Curricular Común Brasileña. 


\section{INTRODUÇÃO}

Destaca-se que, tradicionalmente, a formação é analisada em termos de espaços físicos. No entanto, cada vez mais se mesclam as situações de aprendizagem em contextos formais, não formais e informais na educação científica. Pensar a formação como ambiente de aprendizagem supõe compreender que se aprende a ensinar em diferentes momentos, situações, contextos e meios (Rocha, 2015).

Considerando o desenvolvimento profissional docente (DPD) como um modo contínuo de formação, no qual se aprende em diferentes contextos, é interessante possibilitar proposições formativas do professor como "sujeito criativo investigativo" (homo creare experimentalis) em condições para a produção de aprendizagem profissional. Considerado um dos autores mais representativos da temática de ambientes de aprendizagem prática, Jonassen (1998) aponta que opções viáveis técnica e metodologicamente de aquisição de competências profissionais podem ser consideradas em ambientes de aprendizagem especificamente desenhados.

Nesse contexto, a proposta do curso de formação do sujeito criativo investigativo consiste em envolver os professores em experiências de aprendizagem significativas associadas às modalidades de ações investigativas preconizadas pela nova Base Nacional Comum Curricular (BNCC), que admite um ambiente de características convergentes, mostrando que o aprendizado é ativo. Não há um tempo de espera para o aprendizado, os sujeitos aprendem se envolvendo em tarefas ou atividades significativas que lhes conduzem a indagar, formular perguntas, coletar informações e refletir (Carvalho, 2013).

A formação do homo creare experimentalis é aquela que atua criativamente, amparada por dinâmicas investigativas, ampliando o repertório conceitual, procedimental e atitudinal do docente, principalmente na experimentação investigativa realizada a partir de diferentes materiais e espaços, muito além dos laboratórios científicos.

Nessa perspectiva, aciona-se um conjunto de práticas e atos criativos para proporcionar um aprender contextualizado e, assim, produzir o sujeito criativo investigativo. $\mathrm{O}$ ensino por investigação dentro da tendência da neurociência cognitiva, que defende a possibilidade de treinar o cérebro em determinadas áreas para estimular ideias originais, que é o viés centralizador deste artigo, foi escolhido em função de uma proposição explorada em um estágio de pós-doutoramento. Ao ser compreendida, essa forma de ensino pode ser adaptada para todas as disciplinas da BNCC na atuação professional docente.

$\mathrm{Na}$ discussão a respeito da formação dos processos criativos, consideramos que toda a espécie humana tem a capacidade de criação. O cérebro humano é dotado, do ponto de vista biológico, do poder de criar (Cruz-Guzmán, García-Carmona e Criado, 2011). O ato de criar requer o desenvolvimento da habilidade mental de unificar imagens diferentes em novos contextos e combinações, para se pensar e produzir alterações na realidade (Siry e Kremer, 2011).

A importância da formação do professor da educação básica está norteada pelo Conselho Nacional de Educação (CNE), tendo como principal objetivo orientar uma linguagem comum a fim de revisar as diretrizes dos cursos de licenciatura e pedagogia para que tenham foco na prática da sala alinhadas à BNCC. O texto 
define dez competências gerais e aponta que as formações inicial e continuada devem ser baseadas nas dimensões de "conhecimento", relacionada a expertise do conteúdo, da "prática", que se refere a saber criar e gerir ambientes de aprendizagem, e do "engajamento", que enfatiza o comprometimento do professor com a aprendizagem e interações com a comunidade escolar.

Alinhamos as ideias de Sasseron (2018) e Rocha (2019) em uma concepção construtivista do ensino por investigação e verificamos a necessidade de repensar os papéis do professor e do estudante em sala de aula, de forma que o estudante tenha oportunidades de interagir com o objeto de estudo e com seus pares para organizar o pensamento e elaborar explicações sobre o mundo, utilizando-se de atos criativos investigativos.

Esta proposição se justifica pela articulação com as ideias de metodologias ativas em cooperação entre professores de escolas públicas, alunos de pós-graduação, licenciaturas ou projetos de extensão desenvolvidos no âmbito acadêmico, buscando contribuir de forma a permitir uma ampliação do lastro de pesquisa do referido programa de pós-graduação, tanto para o desenvolvimento de pesquisas acerca da formação docente em espaços formais, não formais e informais de educação científica, como para inovações de ensino e aprendizagem (Rocha e Farias, 2020).

Neste contexto, nos propomos a responder às seguintes questões: Como elaborar aulas e materiais didáticos que tenham essa concepção? Como criar ambientes de investigação que deem oportunidades aos estudantes de construírem conhecimentos de ciências? Mais ainda, como esse processo pode contribuir para a formação do sujeito criativo investigativo com aspectos de protagonismo, reflexões e intervenções para o DPD?

Nessa perspectiva, o presente artigo é resultado de um estágio supervisionado de pós-doutorado na Universidade Federal do Amazonas, no qual tentamos desenvolver o DPD para que professores possam aprimorar a sua criatividade e autonomia formativa, sendo agentes ativos do processo de ensino por investigação e reconhecendo análises do documento curricular de ciências da natureza, que está presente na recém-publicada BNCC, bem como as características do sujeito criativo investigativo (homo creare experimentalis).

\section{DESENVOLVIMENTO PROFISSIONAL DOCENTE E CRIATIVIDADE}

O trabalho apresentado neste projeto busca participar de um movimento que caracteriza o desenvolvimento profissional, por meio de atitudes investigativas permanentes de aprendizagens. Dessa forma, a discussão a respeito da formação dos processos criativos afirma que toda espécie humana tem a capacidade de criação (Arce et al.,2011).

Os autores concebem que o cérebro humano é dotado, do ponto de vista biológico, do poder de criar. Tal ato necessita do desenvolvimento da habilidade mental de unificar imagens diferentes em novos contextos e combinações, para se pensar e produzir alterações na realidade (Arce et al., 2011).

Neste contexto, a expressão DPD pode corresponder a outros termos que são utilizados com frequência, tais como: formações permanente, contínua ou em serviço, desenvolvimento de recursos humanos, aprendizagem ao longo da vida, experiência em exercício, cursos de reciclagem ou de capacitação (Vaillant e Marcelo, 2012). 
Defendemos a noção de que o desenvolvimento profissional é o que se adapta melhor à concepção docente como profissional do ensino, pois o conceito de desenvolvimento tem uma conotação de evolução e continuidade, a qual supera a tradicional justaposição entre formação inicial e aperfeiçoamento dos docentes (Rocha, 2019). O conceito de DPD “[...] tem a ver com a aprendizagem; remete ao trabalho; trata de um trajeto; inclui oportunidades ilimitadas para melhorar a prática; relaciona-se com a formação dos docentes; e opera sobre as pessoas, não sobre os programas" (Vaillant e Marcelo, 2012, p. 169).

Há, portanto, a necessidade de DPD que propicie atualização, renovação de conhecimento, habilidades e capacidades aos professores. Essa deve ser a pauta de prioridade nas políticas educacionais, especialmente nos países em desenvolvimento (Mizukami e Reali,2010; Vaillant e Marcelo,2012). Entender o conceito de DPD é fundamental para desenvolver oportunidades de aprendizagem que promovam capacidades criativas e investigativas nos educadores, as quais lhes permitam melhorar sua prática.

Por um lado, temos a concepção de que os sujeitos produzem cultura, e, portanto, nascem dotados de talentos e aptidões que se desenvolverão por meio de um processo educativo calcado apenas em seus interesses, sendo o professor um guia/ajudante que deve trabalhar apenas com as subjetividades, pois se tem a prerrogativa de que o ensino destrói o ser criativo (Arce et al., 2011).

No entanto, por outro lado, temos a concepção da psicologia sócio-histórica, a qual explicita claramente a necessidade de atividade intencional do ensino e da transmissão de conhecimentos historicamente acumulados como essenciais para que o sujeito comece a se constituir enquanto sujeito investigativo capaz de intervir, modificar e explorar criativamente o mundo em que se encontra.

As concepções que se derivam da estrutura proposta por Rocha (2019) estão em consonância com algumas pesquisas da área (Gatti, 2010; Mizukami, 2010; Fiorentini e Crecci, 2013; Gonçalves, 2013; Tardif, 2013) que tratam a questão do DPD e da aprendizagem dos estudantes que implicam a organização, o sistema ou a cultura em que o desenvolvimento profissional ocorre.

Partindo da premissa de que o sujeito investigativo é influenciado por um conjunto de fatores, a aprendizagem pode ser incluída como um indicador de qualidade, com elementos básicos para explicar o desenvolvimento profissional (Figura 1) em perspectiva do ensino por investigação, que são: conteúdo, processo e contexto.

Conforme a Figura 1, quanto à qualidade de DPD, a característica do "conteúdo" refere-se ao "o que" e está relacionada com o conhecimento, as habilidades, a compreensão de uma disciplina e saber sobre a forma como se aprende. $\mathrm{O}$ "processo" refere-se ao "como" e vincula-se não somente às atividades que são desenvolvidas, mas também à forma de planejá-las, desenvolvê-las e dar-lhes continuidade. As características do "contexto" remetem-se ao "quem, quando, onde e por que" do desenvolvimento profissional. Essas variáveis implicam a organização, o sistema ou a cultura na qual o DPD é desenvolvido.

O conteúdo, os processos e o contexto das atividades de DPD estão articulados em buscar quais significados os sujeitos constroem com suas experiências, mediadas na diversidade de contextos em perspectiva investigativa. A ideia dessa estrutura concebe que, em primeiro lugar, ainda que as relações entre o desenvol- 


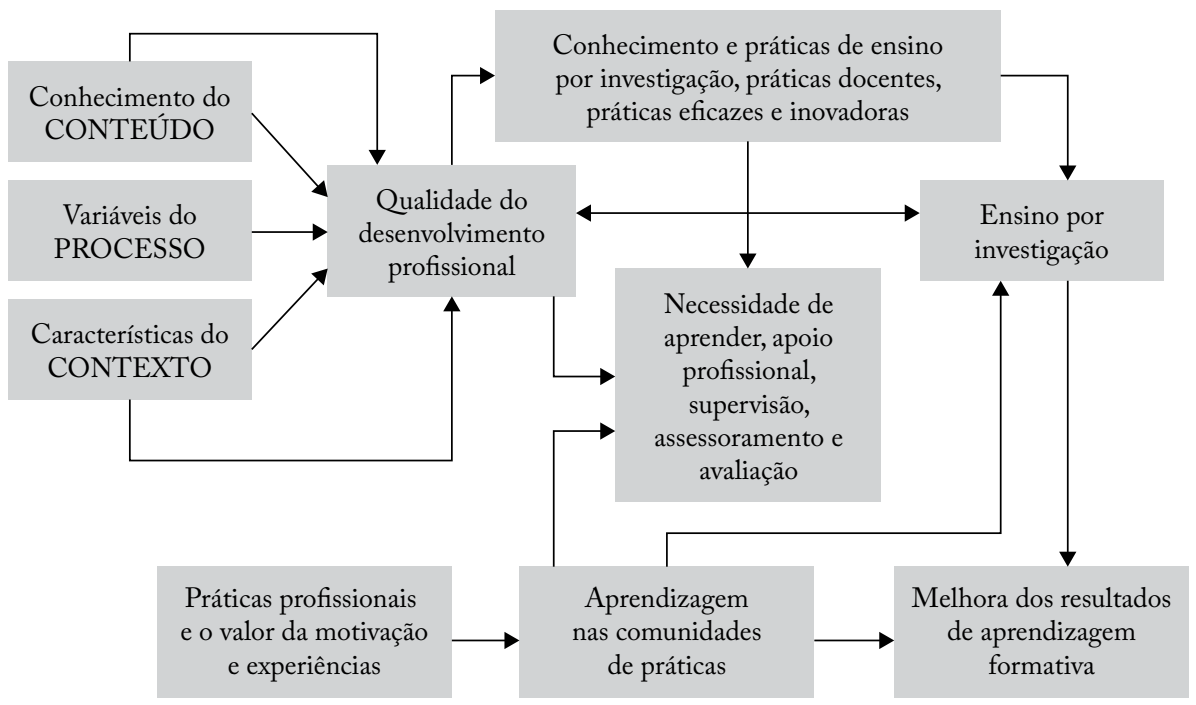

Figura 1 - Desenvolvimento profissional docente e aprendizado em perspectiva do sujeito investigativo.

Fonte: Elaboração do autor com base em Rocha (2019).

vimento profissional e seu aprendizado sejam complexas e multifatoriais, não são malogradas nem caóticas.

Nessa perspectiva, deve-se levar em conta a qualidade do conhecimento e as práticas dos docentes como fatores que influenciam e determinam essa aprendizagem. Se uma atividade de formação "não chega a melhorar o conhecimento e as práticas docentes, pode ser que o desenvolvimento tenha sido com qualidade, mas sua eficácia será baixa" (Vaillant e Marcelo, 2012, p. 178).

Alguns autores buscaram estabelecer a expertise entre docentes e compreender o processo de transformação de um especialista e o que caracterizam estes profissionais (Marcelo García e Vaillant, 2009; Forster et al., 2011; Rossi e Hunger, 2012; Bassoli e Lopes, 2015). Esses autores referem-se ao docente especialista não somente como aquele professor com, ao menos, alguma experiência, mas, sobretudo, a uma pessoa com um elevado nível de conhecimento e destreza.

Para Vaillant e Marcelo (2012), os sujeitos especialistas em qualquer das áreas têm em comum as seguintes características: a) complexidade das destrezas, ou seja, realizam suas ações apoiando-se em uma estrutura diferente e mais complexa que a do principiante, exercendo controle voluntário e estratégico sobre as partes do processo que se desenvolve mais automaticamente no caso do principiante; $b$ ) assinalam a estrutura do conhecimento; e c) representação dos problemas. Portanto, os professores peritos reconhecem e identificam as características de problemas e situações que podem escapar à atenção dos principiantes.

Os sujeitos especialistas entendem a estrutura abstrata do problema e utilizam uma variedade de problemas armazenados em sua memória. Percebe-se que cabe 
ao especialista uma estrutura de conhecimento profunda e multinível, com muitas conexões inter e intraniveladas.

Em consequência, o conhecimento especializado consiste em muito mais do que uma lista de feitos desconectados acerca de determinada disciplina. Pelo contrário, o conhecimento está conectado e organizado em torno de ideias importantes sobre suas disciplinas. Essa organização do conhecimento permite "[...] identificar quando, por que e como" utilizar tais conhecimentos em uma situação particular (Vaillant e Marcelo, 2012, p. 129).

Os autores propõem uma ideia de transformação em docente (Figura 2), que é pertinente para entender o processo de inserção profissional e, como consequência, programar ações formativas investigativas para o processo de transformação docente.

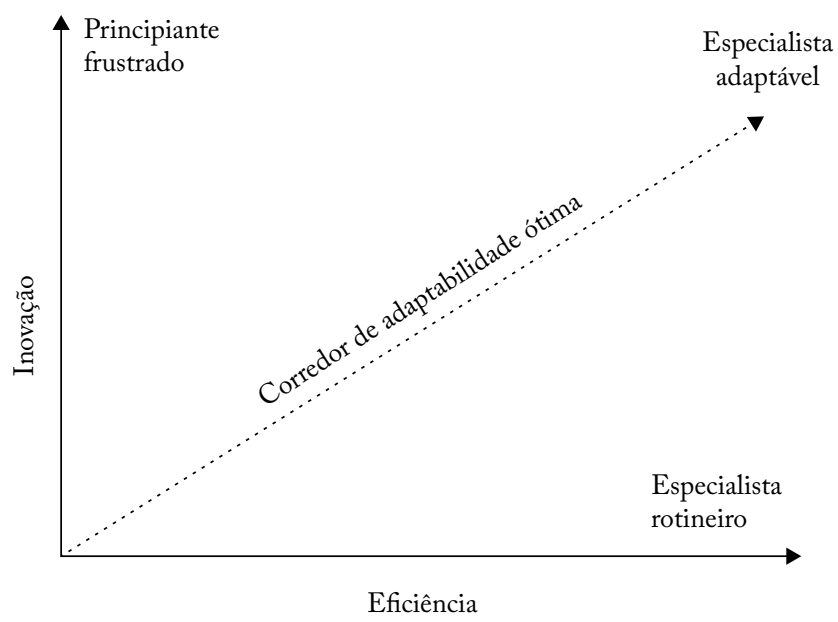

Figura 2 - Processo de transformação em docente.

Fonte: Vaillant e Marcelo (2012, p. 129), com base em Bransford et al. (2005).

Vaillant e Marcelo (2012) apontam uma diferença entre o "especialista rotineiro"e o 'especialista adaptativo'. Ambos continuam aprendendo ao longo de suas vidas. Porém, há a necessidade de se estabelecer distinções entre eles. O primeiro desenvolve um conjunto de competências que aplica ao longo de sua vida, cada vez com mais eficiência. No entanto, o "[...] especialista adaptativo tem maior disposição a mudar suas competências para aprofundá-las e ampliá-las continuamente" (Vaillant e Marcelo, 2012, p. 129).

Outro aspecto são as duas dimensões relevantes no processo de se transformar em um docente especializado: inovação e eficiência. A adaptabilidade em uma só dimensão poderá não apoiar um movimento adaptativo. As pessoas se beneficiam mais de oportunidades de aprendizagem, que fazem parte de um balanço adequado entre as duas dimensões dentro do corredor de (trans)formação. Nesse sentido, muitos programas estão adotando uma ideia de expertise adaptativa como modelo de DPD (Vaillant e Marcelo, 2012). 
Expertise adaptativa é uma característica de inserção à docência, evidenciada pela formação humanística, que teve relativo êxito em países desenvolvidos como Inglaterra, França, Suiça, Japão, Estados Unidos, dentre outros. Em tais locais, a preparação supervisionada dos módulos de inserção à docência, o acompanhamento de um mentor ou tutor especialista, a participação de docentes novatos em seminários, a comunicação constante com diretores de estabelecimento de ensino e o tempo dedicado a planejar aulas e ao trabalho colaborativo (Vaillant e Marcelo, 2012) possibilitaram a eficácia de formação, que se destaca pela destreza e competência na execução de um trabalho, considerando a experiência e a prática com base em conhecimentos contínuos.

\section{MODALIDADES DE AÇÕES INVESTIGATIVAS NA BASE NACIONAL COMUM CURRICULAR}

Muito se fala atualmente sobre a relevância da centralidade do estudante no processo de ensino e aprendizagem. Para Ursi e Scarpa (2016), a perspectiva tradicional, em que o ensino é visto como unidirecional e o professor é considerado o detentor do conhecimento e o transmite para os estudantes que o recebem passivamente, não tem se mostrado nem efetiva nem motivadora para a construção de conhecimentos científicos.

Alinhando-se com uma concepção construtivista de educação, verifica-se a necessidade de repensar os papéis do professor e do estudante em sala de aula, de forma que este tenha oportunidades de interagir com o objeto de estudo e seus pares para organizar o pensamento e elaborar explicações sobre o mundo, utilizando-se de conceitos científicos.

A BNCC para o ensino fundamental destaca o letramento científico na área de ciências da natureza e menciona que o ensino das ciências deve ocorrer na articulação com outros campos de saber e que "precisa assegurar aos alunos deste nível de ensino o acesso à diversidade de conhecimentos científicos produzidos ao longo da história, bem como a aproximação gradativa aos principais processos, práticas e procedimentos da investigação científica” (MEC, 2017, p. 319).

Como forma de orientar o professor no planejamento de atividades e sequências didáticas pautadas no ensino por investigação, há diversas indicações de etapas que constituem o processo investigativo na literatura de pesquisa. Sasseron (2018) apresenta e discute o ensino de ciências por investigação e o desenvolvimento de práticas, mirando para a BNCC, apresentando impressões sobre os elementos que precisam ser considerados para a efetiva concretização dos pressupostos de tal documento em sala de aula.

Conforme Sasseron (2018), seguindo as ideias expostas na apresentação do processo investigativo, a BNCC afirma que o ensino de ciências da natureza deve ocorrer por meio da promoção de situações investigativas em sala de aula, em que sejam atendidas as modalidades de ações investigativas (Figura 3) da BNCC para o ensino fundamental. ${ }^{1}$

1 O documento utilizado como referência é o artigo de Sasseron (2018), que foi baseado na versão aprovada pelo Conselho Nacional de Educação, em dezembro de 2017, e publicado no site do Ministério da Educação (MEC), em 20 de dezembro do mesmo ano. A versão digital pode ser encontrada em: http://basenacionalcomum.mec.gov.br. 


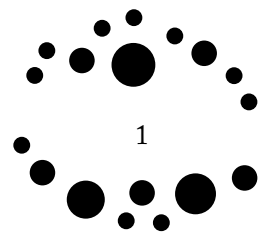

Definição do problema

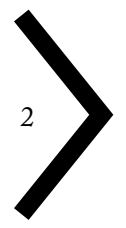

Levantamento, análise e representação

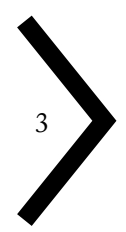

Comunicação

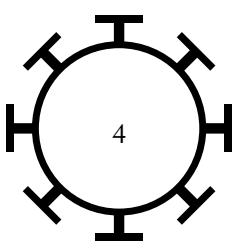

Intervenção

Figura 3 - Modalidades de ação na promoção de situações investigativas - Base Nacional Comum Curricular.

Fonte: Elaboração do autor com base na Base Nacional Comum Curricular para o ensino fundamental (MEC, 2017).

Na modalidade de ação, "definição do problema" consiste em observar o mundo a sua volta e fazer perguntas, analisar demandas, propor hipóteses, delinear problemas e planejar investigações, por meio do estímulo à curiosidade dos alunos sobre um tópico ou de sua contextualização. Na conceitualização, questões/perguntas são formuladas e explicações provisórias são elaboradas, baseadas em conhecimento prévio. Não há investigação sem problema.

Assim, a primeira preocupação do professor consiste em formular um problema que instigue e oriente o trabalho a ser desenvolvido com os alunos. Além disso, a pergunta precisa ser considerada um problema pelos alunos, o que implica explorar as ideias criativas que estes têm a respeito do assunto, dialogar com elas, confrontá-las com outras e duvidar delas.

Na modalidade de "levantamento, análise e representação", a BNCC propõe ações investigativas, tais como: planejar e realizar atividades de campo (experimentos, observações, leituras, visitas, ambientes virtuais etc.); desenvolver e utilizar ferramentas, inclusive digitais, para coleta, análise e representação de dados (imagens, esquemas, tabelas, gráficos, quadros, diagramas, mapas, modelos, representações de sistemas, fluxogramas, mapas conceituais, simulações, aplicativos etc.); avaliar informação (validade, coerência e adequação ao problema formulado); elaborar explicações e/ou modelos; associar explicações e/ou modelos à evolução histórica dos conhecimentos científicos envolvidos; selecionar e construir argumentos com base em evidências, modelos e/ou conhecimentos científicos; aprimorar seus saberes e incorporar, gradualmente e de modo significativo, o conhecimento científico; e desenvolver soluções para problemas cotidianos usando diferentes ferramentas, inclusive digitais.

Sasseron (2018) chama a atenção para o grande número de ações voltadas à esta modalidade quando comparado àquele referente às demais modalidades. Para Sasseron (2018), o trabalho com tais modalidades e a frequência de seu surgimento em aulas estarão sob responsabilidade mais direta do professor da turma, mas a baixa ênfase nas ações voltadas à "Definição de problemas" à "Intervenção" denuncia, de modo implícito, uma visão de ensino de ciências cujo protagonismo dos estudantes alia-se mais diretamente ao trabalho para o desenvolvimento de entendimento sobre conhecimentos conceituais das ciências. 
$\mathrm{Na}$ Comunicação, as ações sugerem organizar e/ou extrapolar conclusões; relatar informações de forma oral, escrita ou multimodal; apresentar, de forma sistemática, dados e resultados de investigações; participar de discussões de caráter científico com colegas, professores, familiares e comunidade em geral; e considerar contra-argumentos para rever processos investigativos e conclusões.

Cabe destacar a configuração por meio das competências gerais definidas pela BNCC, que mobilizam propostas de construção de conhecimentos conceituais e procedimentais, o desenvolvimento de habilidades e, ainda, a formação de valores e atitudes voltadas à resolução das demandas complexas, a serem construídas no percurso da educação básica.

Nesse sentido, a fim de socializar e possibilitar o processo de análise, reflexão, compreensão e eficácia de atos de ensino do professor no contexto da BNCC, destaca-se a importância da formação continuada como um dos elementos fundamentais de aspectos pedagógicos e técnicos do profissional professor. Com isso, há a prioridade e colaboração das dimensões pessoais e culturais do professor, tais como a capacidade de adaptação às novas mudanças, superando as dificuldades encontradas no decorrer do processo formativo; a proposta com autonomia de estratégias significativas de ensino e aprendizagem à comunidade escolar, portanto, agindo com inovação e eficácia de sua prática e como agente transformador dos contextos escolar, social e profissional.

Ainda com referência às modalidades de ações investigativas, a "Intervenção" busca implementar soluções e avaliar sua eficácia para resolver problemas cotidianos e desenvolver ações de intervenção para melhorar a qualidade de vida individual, coletiva e socioambiental (MEC, 2017, p. 321).

Essas modalidades, bem como outras temáticas envolvidas no documento da BNCC, tais como "Alfabetização e Letramento", "Interdisciplinaridade e Planejamento", "Diversidade" e "Formação Continuada", devem ser objeto de reflexão por todos os atores envolvidos no ensino por investigação.

Assim, torna-se necessário ressignificar as ações de DPD por meio de formação do sujeito criativo investigativo, também dentro do corredor de adaptabilidade ótima de uma formação do especialista adaptável, no sentido de auxiliar e colaborar com a efetivação da BNCC, que tem como objetivo a promoção da universalização do conhecimento.

\section{FORMAÇÃO DO SUJEITO CRIATIVO INVESTIGATIVO}

Tendo em vista a relevância da criatividade como resultado de processos cognitivos, propomos relações formativas (Figura 4), enfatizando proposições de atividades no ensino de ciências, associadas às modalidades de ações investigativas da BNCC e de fases da criatividade (Piletti, 1997), as quais, em nosso entendimento, permitem dinamizar o desenvolvimento do homo creare experimentalis no contexto de DPD.

Inspirado principalmente na proposta de qualidade de DPD (Rocha, 2019) e de aspectos de criatividade (Piletti, 1997), construímos uma proposição de instrumento de análise, visando propiciar um maior detalhamento das ações 


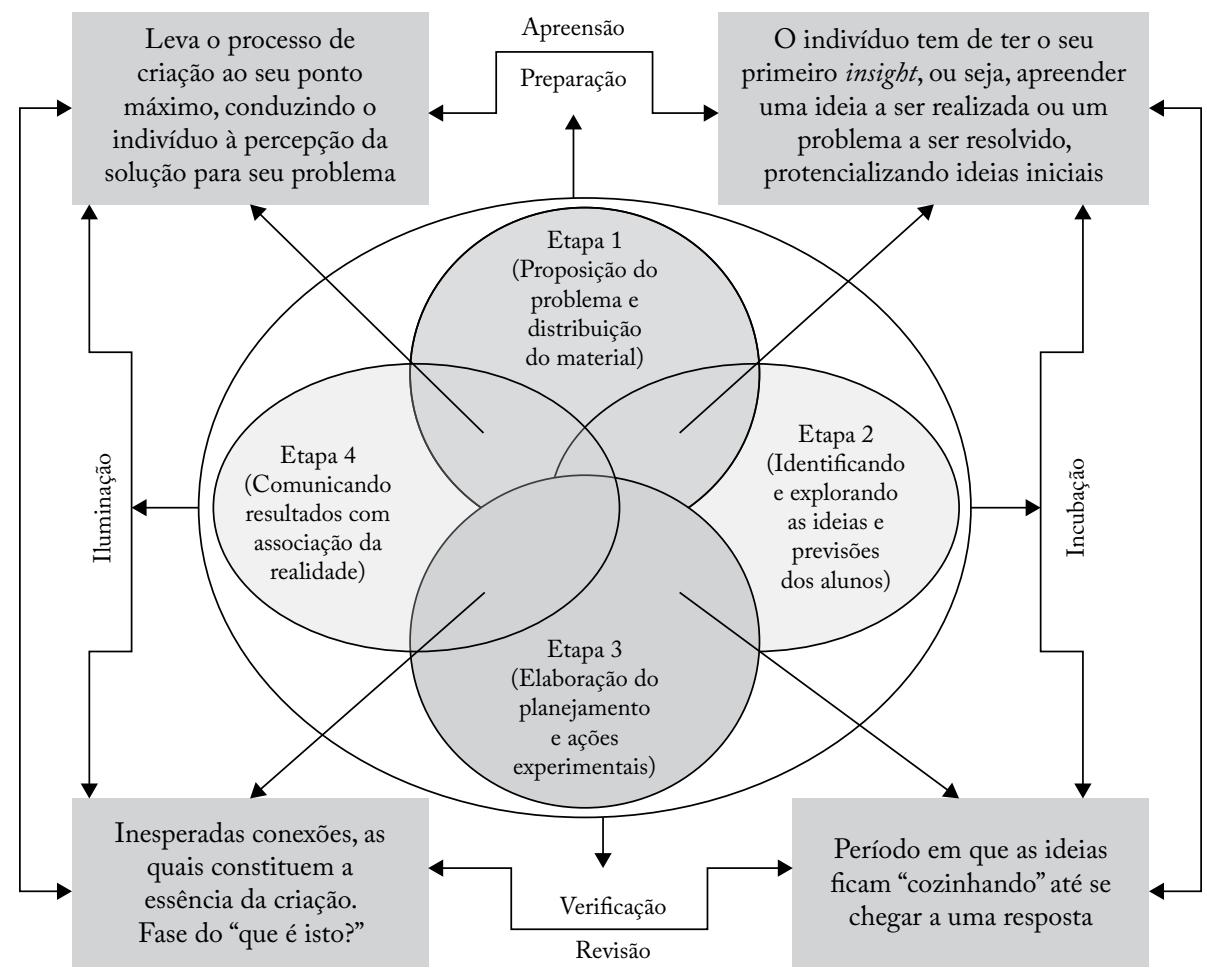

Figura 4 - Relações formativas do sujeito criativo investigativo.

Fonte: Elaboração do autor de acordo com a Base Nacional Comum Curricular (MEC, 2017) e Piletti (1997).

em atividades do ensino de ciências na busca por uma construção mais refinada e, portanto, possibilitando uma compreensão de diferentes aspectos relacionados à interação para o DPD.

Essas relações levam em conta a triangulação da forma proposta, contemplando os processos de criação considerados ao sujeito criativo investigativo e que se traduzem pela capacidade de reter imagens extraídas das experiências sociais anteriores para combiná-las com elementos novos, como capacidade de abstração, imaginação e raciocínio lógico.

Diante dessa proposição, destacamos que o ensino por investigação não é sinônimo de experimentação. A realização de experimentos e o uso de laboratório são estratégias importantes no ensino de ciências, mas não são as únicas, nem as mais necessárias, para as atividades investigativas. A coleta de dados e informações para responder questões de pesquisa pode ser realizada por meio de diferentes estratégias didáticas: observações, comparações entre fenômenos, livros, internet, filmes, jogos, simulações etc. O importante é contextualizar a situação investigativa para que questões possam ser efetivamente respondidas, por meio da construção conjunta de explicações sustentadas em evidências coletadas de diversas fontes (Ursi e Scarpa, 2016). 
Piletti (1997) afirma que a criatividade acontece gradativamente em fases ou etapas reconhecíveis. Para tal autor, o processo criativo se desenvolve durante um período e este pode ser analisado como sendo composto de vários estágios da atividade criativa. $\mathrm{O}$ autor propõe o desenvolvimento da criatividade em cinco fases: apreensão, preparação, incubação, verificação e iluminação.

A BNCC, da área das ciências da natureza, homologada em 2017, norteia nove competências específicas e 114 habilidades que o estudante deve desenvolver ao concluir o ensino fundamental, considerando as relevâncias científica, tecnológica, social e cultural. Entendemos que tal documento não pretende homogeneizar as práticas docentes, mas sugerir caminhos que possibilitem a promoção da autonomia criativa investigativa de cada professor no aperfeiçoamento de seu trabalho.

Nesse contexto, a primeira fase é a da "apreensão", caracterizada por uma demorada preparação consciente, seguida por intervalos de atividade não consciente. $\mathrm{O}$ indivíduo tem de ter o seu primeiro insight, ou seja, apreender uma ideia a ser realizada ou um problema a ser resolvido. Até o momento da 'apreensão', o criador não teve inspiração, mas apenas a noção de algo a ser feito.

$\mathrm{Na}$ sequência, vem a fase da "preparação", que é constituída pela investigação das potencialidades da ideia inicial. O indivíduo lê, anota, discute, indaga e coleciona. Nesta fase, a modalidade de ação investigativa abre possíveis soluções, ponderando a viabilidade de cada proposta. Esta fase também inclui o meio criador. A criação requer técnica, que pode ser bruta ou refinada, conforme a natureza do meio e da atividade.

Deve-se levar em conta que, na BNCC, as unidades temáticas das ciências da natureza são as mesmas para todo o ensino fundamental, mas os objetos de conhecimentos alteram-se, revelando aprofundamento e mudança de foco da discussão sobre a temática de um ano escolar para o outro. As habilidades figuram como objetivos a serem desenvolvidos na abordagem dos objetos de conhecimento para tal ano escolar (Sasseron, 2018).

A outra fase é a "incubação", caracterizada pelo trabalho do inconsciente, que, sem limites e desimpedimentos pelo intelecto literal, faz as inesperadas conexões, as quais constituem a essência da criação. É a fase de verificação ou revisão, na qual o criador precisa distinguir, na sua produção, o que é válido, pois a fase de iluminação é falível. Embora a apresentação das fases da atividade criativa seja tão evidente, não há como separá-las.

Seguindo a ordem, aparece a fase da "iluminação", que leva o processo de criação ao seu ponto máximo, pois, de repente, o criador percebe a solução para o seu problema, o conceito que enfoca todos os fatos ou o pensamento que completa as ideias trabalhadas, conduzindo o indivíduo à percepção da solução para seu problema. Desse modo, a BNCC deve subsidiar a prática pedagógica do professor, bem como o desenvolvimento integral dos seus alunos.

Nessa perspectiva, na ação investigativa 1 ("Definição do problema"), associa-se à fase de "apreensão", considerando a novidade, o que Piletti (1997) concebe como a primeira característica da criatividade. Uma ideia, um comportamento ou um objeto são criativos na medida em que são novos. Essa novidade pode referir-se tanto ao sujeito que cria, quanto ao conhecimento existente naquele momento. 
Dependendo da ação investigativa desenvolvida, instiga-se a curiosidade dos sujeitos, que, em um ambiente lúdico e estimulante, começam a fazer várias tentativas para soluções de problemas. Nessa "apreensão", o momento criativo não acontece de imediato. $\mathrm{O}$ ato criador é resultado dessas tentativas, do surgimento de uma ideia para resolução do problema (Rocha e Malheiro, 2017).

$\mathrm{Na}$ resolução de problemas ao qual se propõe o ensino por investigação, o professor deve permitir a colaboração dos alunos entre si na busca de soluções, comportamento que indica aprendizagem atitudinal, bem como discussões que busquem ideias como hipóteses, e, sempre que possível, deve testá-las. É preciso verificar quem não se desenvolve nem em termos de atitude nem em termos de processo (Rocha, 2015).

Considerando as análises de Sasseron (2018), é digno de nota que o trabalho com as modalidades de ações investigativas "definição de problemas" foi identificado em apenas uma habilidade da BNCC, e as ações relacionadas à modalidade "intervenção" não foram encontradas. Assim, determinadas ações e práticas das ciências são mais intensas na BNCC, enquanto outras, igualmente importantes e necessárias de serem trabalhadas em sala de aula, ficam à margem do texto.

Em meio a dúvidas, impasses e incertezas, a formação do homo creare experimentalis é requisitada como uma estratégia do discurso científico, merecendo que o DPD seja considerado com cautela, pois as ciências são reconhecidas por seu caráter investigativo sustentado pela constituição das resoluções de problemas. Assim, a verdade científica é vivenciada pelos professores em formação, por meio de suas produções internas acerca de seus métodos e procedimentos. A verdade científica produzida, portanto, quando se revela, registra, testa e teoriza sobre um fenômeno experimentado (Cardoso e Paraíso, 2015).

Nesse contexto, Rocha e Malheiro $(2017 ; 2018)$ consideram que a interrogação é outra condição da atividade criativa, corroborando com Piletti (1997), em que é tão importante fazer e refazer perguntas quanto respondê-las no pensamento criador. O papel do professor nesta etapa é verificar se os sujeitos entenderam o problema proposto e deixá-los trabalhar (Cortella e Casadei, 2009).

Além disso, há também a parte afetiva, pois é muito mais fácil propor suas ideias a um colega do que ao professor. Como o erro nesta etapa é importante para separar as variáveis que interferem daquelas que não interferem na resolução do problema, "[...] os sujeitos precisam errar, isto é, propor coisas que pensam testá-las e verificar que não funcionam” (Carvalho, 2013, p. 12), ou seja, experimentar sem medo de errar (Silva, Machado e Tunes, 2010).

Com base nesses pressupostos e da manipulação do material didático disponibilizado, é que os sujeitos na modalidade de ação investigativa 2 ("Levantamento, análise e representação") vão levantar hipóteses/previsões e experimentá-las para resolver o problema. Para que ocorra uma verdadeira criação, a receptividade é a primeira das condições, pois as ideias criadoras não podem ser forçadas, e, se não há receptividade, elas não surgem.

A fase de "Preparação" consiste num trabalho sistemático de constituição de informações relacionadas à ideia original e convenientemente organizadas, para que possam ser utilizadas quando necessário. Tal condição nutre a imaginação e fortalece o ato criador, pois oferece uma série de novas abordagens em relação ao 
problema, evidencia novos caminhos para a solução do mesmo e ajuda o sujeito da atividade criativa a pensar mais profundamente e de modo mais global a respeito do ato criador (Piletti, 1997).

Ressalta-se que a própria BNCC, em seu texto introdutório, faz questão de afirmar que o currículo deve ser complementar às ideias expostas no documento (Sasseron, 2001). Nesse sentido, a formação aqui proposta pode servir de subsídio preparatório para a avaliação e consideração de quais elementos de criatividade em ciências da natureza precisam ser atendidos nos momentos de ações investigativas, em que a proposta curricular começa a se expandir na educação brasileira.

Além da "apreensão" e "preparação", a receptividade, a dedicação e o desprendimento também são condições essenciais para o desenvolvimento da criatividade. $\mathrm{Na}$ fase de "incubação", o trabalho é inconsciente. Os períodos de "preparação" e "incubação" podem se alternar no mesmo ato criador. Conforme mencionado, a "incubação" consiste na fase em que a pessoa deixa de lado as informações constituídas e dedica-se a outras atividades, parecendo esquecer-se do seu trabalho. Em tal fase, o inconsciente realiza associações, organiza ideias e trabalha sobre as questões levantadas a partir das informações colhidas (Kneller, 1999).

$\mathrm{Na}$ elaboração do planejamento e modalidade de ação investigativa 3 ("Comunicação"), manifestam-se as questões levantadas. Nesta etapa, o sujeito se envolve profundamente em seu trabalho para reunir a energia necessária à concentração que a atividade criativa exige. Ao mesmo tempo, é preciso cuidado quando o sujeito focaliza em demasia seu trabalho, podendo limitar seu pensamento e prejudicar a criatividade. Portanto, é necessário desprendimento para que se consiga ver o processo como um todo, permitindo, assim, outras formas de leitura e observação da ação criativa (Piletti, 1997). Ainda nesta fase, a imaginação e o julgamento são igualmente condições da criatividade. A imaginação produz ideias, porém não as comunica; já o julgamento comunica as ideias, mas não as produz. A criatividade só ocorrerá se houver cooperação entre a imaginação e o julgamento, uma vez que a ação criativa é, ao mesmo tempo, produção e comunicação dos resultados, associando-os com a realidade.

A vinculação citada é representada na modalidade de ação investigativa 4 ("Intervenção"). Pode-se considerar o momento culminante do processo criativo, pois é nele que aparece a solução do problema. Embora os sujeitos tenham limites muito claros, no processo investigativo, não se esperam atos criativos extraordinários. O problema não é estudar o fenômeno de maneira neutra, e sim de "[...] criar condições segundo as quais esse fenômeno dará testemunho" (Stengers, 1990, p. 84). O desafio está em respeitar os limites dos sujeitos, para que possam aprender ciência com alegria e prazer.

Nesse desenvolvimento se dá a "verificação", na qual o criador tenta dar forma final à inspiração que teve, podendo conseguir fazê-lo ou não. Caso não consiga, convém abandonar a primeira "apreensão" e procurar uma nova ideia, recomeçando o processo. Algumas vezes, após o momento de "iluminação", leva-se tempo para elaborar e rever previsões ou hipóteses (Piletti, 1997).

Sustenta-se que os sujeitos criativos investigativos possuem capacidades inatas para construir representações sobre a realidade natural, podendo exercer 
seu pensamento sobre as coisas e à medida que expõem e socializam suas dúvidas e descobertas para o professor e seus colegas, podem rever as explicações criativas sobre o que ocorre em fenômenos naturais e elaborar compreensões dentro de seus graus cognitivos.

Kneller (1999) considera que, no processo criativo, há um impulso para criar. Segue-se a este um período em que o criador recolhe material e investiga diferentes métodos de trabalhá-lo. Em seguida, vem um tempo de "incubação", no qual a obra criadora procede inconscientemente. Então, surge o "momento da 'iluminação', e o inconsciente anuncia de súbito os resultados de seu trabalho" (Kneller, 1999, p. 73).

O processo investigativo distribui encantamentos sobre o DPD em ciências. Se tais sujeitos se posicionam como creare experimentalis, é porque nas modalidades de ação investigativas propostas na BNCC pode-se produzir um desejo pela empiria, ao se propor a solução de um problema, graduando o desafio de modo que as dificuldades possuam um grau compatível com a fase criativa do sujeito, por isso não podem ser tão fáceis que não motivem o desenvolvimento de ações criativas, nem tão difíceis a ponto de levar o sujeito a desistir (Arce et al., 2011).

Com o discurso de DPD dentro de metodologias ativas na educação para a ciência, "[...] o sujeito pode ser o agente ativo graças ao qual a verdade emerge" (Foucault, 2010, p. 65). O sujeito estará a "[...] aprender, conhecer e compreender a ação humana e os conhecimentos que dela frutificarem e acumularem-se em práticas e objetos, na vida e no mundo" (Arce et al., 2011, p. 61).

É nessa clareza de que as modalidades de ações investigativas da BNCC e seus possíveis resultados envolvem concepções e ideias criadas, desenvolvidas por sujeitos que se identificam com a ciência, é que os sujeitos se posicionam nesse discurso e passam a agir de acordo com suas verdades. Sujeitos investigativos da criatividade, ou sujeitos creare experimentalis, no entanto, não são cientistas ou escolares científicos.

Esse desenvolvimento profissional do sujeito criativo investigativo trata-se de um conhecer, aprender e compreender o mundo real. Assim, conhecimento científico é um resultado do desenvolvimento de criatividades, conceitos e teorias para se conhecer, compreender e aprender o mundo e, ao ensinar-se ciências, não se pode prescindir dele. Vê-se, portanto, que a criatividade investigativa de professores não restringe o seu alcance aos laboratórios científicos. Essa abordagem didática pode estar presente em espaços formais, informais e não formais de educação científica, desenvolvendo formação e DPD (Ferreira, Marandino e Selles, 2009; Cascais e Terán, 2014).

Nessa perspectiva criativa experimental, aciona-se um conjunto de práticas e técnicas para proporcionar um aprender contextualizado e, assim, produzir o bomo creare experimentalis, ou seja, o sujeito investigativo. Conforme Rocha, Malheiro e Teixeira (2018), é possível encontrar demandas ao sujeito investigativo, aquele que desenvolve processos de imaginação, com criatividade e autonomia, envolvendo a resolução dos problemas propostos e fazendo uso de pesquisa, ensino ou extensão. Além disso, pode-se explorar ideias e previsões, elaborando possíveis planos de ações e experimentando o planejado, comunicando e socializando os resultados. 


\section{CONSIDERAÇÕES FINAIS}

As ações criativas investigativas de professores permitem o DPF, desenvolvendo conhecimento científico com expertise adaptativa por meio da concepção do inquiry (ensino por investigação). O sujeito criativo investigativo, ou seja, o homo creare experimentalis é aquele que atua criativamente e amparado por distintas dinâmicas, ampliando seu repertório conceitual, procedimental e atitudinal, por meio da criação de ações científicas com alegria e prazer.

Dessa forma, a criatividade e a autonomia com o uso de modalidades de ações investigativas propostas pela BNCC possibilitam a resoluções de problemas, fazendo uso de metodologias ativas de aprendizagem. Portanto, é uma forma de consolidar o inquiry na formação e nos atos de ensino de professores para educação científica.

A formação e a execução nesta proposição de DPD devem ser de maneira interativa e colaborativa, a fim de tentar analisar o entendimento da complexa dinâmica envolvendo os processos de formação, ensino e aprendizagem em perspectiva do sujeito investigativo, que tem motivado o desenvolvimento da pesquisa, ensino e extensão relacionadas ao discurso de formação de professores, buscando melhorar seu impacto na condução de desenvolvimento formativo para o ensino por investigação na educação básica.

Nesta metodologia de formação, proporciona-se um ambiente alternativo de ensino em prol da popularização da ciência, da iniciação científica e da formação inicial e continuada de professores. Nesse contexto, a formação do sujeito criativo investigativo é uma das estratégias que ajuda professores a desenvolverem nas crianças processos de criativos, percepções de fenômenos e compreensão de conceitos e fenômenos observáveis. Precisamos confiar nos professores que temos no país, valorizando sua capacidade e criatividade pedagógicas.

Portanto, acreditamos que nossa proposição pode contribuir para o desenvolvimento de capacidades inovadoras e eficientes na formação de especialistas, que sejam adaptáveis para atuação nas educações básica e superior para o desenvolvimento de pesquisas na área de DPF em perspectiva do ensino por investigação, alinhadas com as necessidades contemporâneas.

\section{REFERÊNCIAS}

ARCE, A.; SILVA, D. A. S. M.; VAROTTO, M.; MIGUEL, C. C. Ensinando ciências na educação infantil. Campinas: Alínea, 2011.

BASSOLI, F.; LOPES, J. G. S. Formação continuada de professores de ciências em um grupo colaborativo: construindo caminhos. In: ENCONTRO NACIONAL DE PESQUISA EM EDUCAÇÃO EM CIÊNCIAS, 10., 2015, Águas de Lindoia.Anais [...]. Águas de Lindoia: ABRAPEC, 2015. p. 1-8.

BRANSFORD, J.; DARLING-HAMMOND, L.; LEPAGE, P. Introduction. In: DARLING-HAMMOND, L.; BRANSFORD, J. (ed.). Preparing teachers for a changing world. San Francisco: Jossey Bass, 2005. p. 1-39. 
CARDOSO, L. R.; PARAÍSO, M. A. Dispositivo da experimentação e produção do sujeito homo experimentalis em um currículo de ciências. Educação em Revista, Belo Horizonte, v. 31, n. 3, p. 299-320, set. 2015. https://doi.org/10.1590/0102-4698121155 CARVALHO, A. M. P. O ensino de ciências e a proposição de sequências de ensino investigativas. In: CARVALHO, A. M. P. (org.). Ensino de ciências por investigação: condições para implementação em sala de aula. São Paulo: Cengage Learning, 2013. p. 1-20.

CASCAIS, M. G. A.; TERÁN, A. F. Educação formal, informal e não formal na educação em ciências. Ciência em Tela, Rio de Janeiro, v. 7, n. 2, p. 1-10, 2014.

CORTELLA, M. S.; CASADEI, S. R. O que é a pergunta? 2. ed. São Paulo: Cortez, 2009.

CRUZ-GUZMÁN, M.; GARCÍA-CARMONA, A.; CRIADO, A. Aprendiendo sobre los cambios de estado en educación infantil mediante secuencias de preguntapredicción-comprobación experimental. Enseñanza de las Ciencias, Barcelona, v. 35, n. 3, p. 175-193, 2011.

FERREIRA, M. S.; MARANDINO, M.; SELLES, S. E. Ensino de biologia: histórias e práticas em diferentes espaços educativos. São Paulo: Cortez, 2009.

FIORENTINI, D.; CRECCI, V.M. Desenvolvimento profissional docente: um termo guarda-chuva ou um novo sentido à formação? Formação Docente, Belo Horizonte, v. 5, n. 8, p. 11-23, jan./jun. 2013.

FORSTER, M. M. S.; VEIT, C. M.; ANTICH, A. V.; REIS, M. F. G. A formação continuada de professores no espaço escolar: impactos na prática docente. Revista Diálogo Educacional, Curitiba, v. 11, n. 33, p. 497-514, 2011. http://dx.doi. org/10.7213/rde.v11i33.4417

FOUCAULT, M. Vigiar e punir: nascimento da prisão. Petrópolis: Vozes, 2010.

GATTI, B. Formação de professores no Brasil: características e problemas. Educação \& Sociedade, Campinas, v. 31, n. 113, p. 1355-1379, 2010. https://doi.org/10.1590/ S0101-73302010000400016

GONÇALVES, T.V. O. Formação de professores de ciências e matemáticas: desafios do século XXI. São Paulo: Livraria da Física, 2013.

JONASSEN, D. Designing constructivist learning environments. In: REIGELUTH, C. M. (ed.). Instructional theories and models. Mahwah, NJ: Lawrence Erlbaum, 1998. p. 215-239.

KNELLER, G. F. Arte e ciência da criatividade. 14. ed. São Paulo: Ibrasa, 1999.

MARCELO GARCÍA, C.; VAILLANT, D. Desarrollo profesional docente: ¿Cómo se aprende a enseñar? Madrid: Narcea, 2009.

MEC - MINISTÉRIO DA EDUCAÇÃO. Base Nacional Comum Curricular. Brasília, DF: Secretaria da Educação Básica, 2017.

MIZUKAMI, M. G. N.; REALI, A. Escola e aprendizagem da docência: processos de investigação e formação. São Carlos: EdUFSCar, 2010.

PILETTI, N. Psicologia educacional. 3. ed. São Paulo: Ática, 1997. 
ROCHA, C. J. T. Ensino da química na perspectiva investigativa em escolas públicas do município de Castanhal-Pará. 2015.109 f. Dissertação (Mestrado) — Universidade Federal do ABC, Santo André, 2015. Disponível em: http://bdtd.ibict.br/vufind/ Record/UFBC_23337e3014f9e7a1a171d7fc6dd3b32c. Acesso em: 10 ago. 2021.

ROCHA, C. J. T. Desenvolvimento profissional docente em perspectiva do ensino por investigação em um Clube de Ciências da UFPA. 2019.185 f. Tese (Doutorado em Educação em Ciências e Matemáticas) — Universidade Federal do Pará, Belém, 2019. ROCHA, C. J. T.; FARIAS, S. A. Metodologias ativas de aprendizagem possíveis ao ensino de ciências e matemática. Revista REAMEC, Cuiabá, v. 8, n. 2, p. 69-87, 2020. Disponível em: https://doi.org/10.26571/reamec.v8i2.9422. Acesso em: 10 ago. 2021. ROCHA, C. J. T.; MALHEIRO, J. M. S. Clube de ciências Prof. Dr. Cristovam W. P. Diniz e o ensino investigativo no município de Castanhal-Pará. In: ENCONTRO NACIONAL DE ENSINO DE CIÊNCIAS POR INVESTIGAÇÃO, 1., 2017, São Paulo. Pôster. São Paulo: Faculdade de Educação, Universidade de São Paulo, 2017.

ROCHA, C. J. T.; MALHEIRO, J. M. S. Interações dialógicas na experimentação investigativa em um Clube de Ciências: proposição de instrumento de análise metacognitivo. Amazônia - Revista de Educação em Ciências e Matemáticas, Belém, v. 14, n. 29, p. 193-207, 2018. http://dx.doi.org/10.18542/amazrecm.v14i29.5476

ROCHA, C. J. T.; MALHEIRO, J. M. S.; TEIXEIRA, O. P. B. Experimentação investigativa e produção do sujeito creare experimentalis em um Clube de Ciências. In: ENCONTRO DE EDUCAÇÃO EM CIÊNCIAS E MATEMÁTICA, 1., 2018, São Paulo. Anais... São Paulo: UFSCar, 2018. Educação em ciências e matemática: tendências e proposições. [Resumo].

ROSSI, F.; HUNGER, D. As etapas da carreira docente e o processo de formação continuada de professores de educação física. Revista Brasileira de Educação Física e Esporte, São Paulo, v. 26, n. 2, p. 323-338, 2012. https://doi.org/10.1590/S180755092012000200014

SASSERON, L.H. Ensino de ciências por investigação e o desenvolvimento de práticas: uma mirada para a Base Nacional Comum Curricular. Revista Brasileira de Pesquisa em Educação em Ciências, Belo Horizonte, v. 18, n. 3, p. 1.061-1.085, 2018. https:// doi.org/10.28976/1984-2686rbpec20181831061

SILVA, R. R.; MACHADO, P. F. L.; TUNES, E. Experimentar sem medo de errar. In: SANTOS, W. L.; MALDANER, O. A.; MACHADO, P. F. L. (orgs.). Ensino de química em foco. Ijuí: Unijuí, 2010. p. 231-261.

SIRY, C.; KREMER, I. Children explain the rainbow: using young children's ideas to guide science curricula. Journal of Science Education and Technology, Berlin, v. 20, n. 5, p. 643-655, 2011. Disponível em: http://dx.doi.org/10.1007/s10956-011-9320-5. Acesso em: 5 abr. 2020.

STENGERS, I. Quem tem medo da ciência?: ciências e poderes. São Paulo: Siciliano, 1990.

TARDIF, M. A profissionalização do ensino passados trinta anos: dois passos para frente, três para trás. Educação \& Sociedade, Campinas, v. 34, n. 123, p. 551-571, 2013. https://doi.org/10.1590/S0101-73302013000200013 
URSI, S.; SCARPA, D. L. Ensino de ciências por investigação: sequência didática "Enigma do costão rochoso". São Paulo: Instituto de Biociências, Universidade de São Paulo, 2016.

VAILLANT, D.; MARCELO, C. Ensinando a ensinar: as quatro etapas de uma aprendizagem. Curitiba: UFTPR, 2012.

\section{SOBRE O AUTOR}

Carlos José Trindade da Rocha é doutor em educação em ciências e matemática pela Universidade Federal do Pará (UFPA). Professor da mesma instituição e efetivo da Secretaria de Estado de Educação do Pará (SEE-PA). E-mail: carlosjtr@hotmail.com

Conflitos de interesse: $\mathrm{O}$ autor declara que não possui nenhum interesse comercial ou associativo que represente conflito de interesses em relação ao manuscrito.

Financiamento: $\mathrm{O}$ estudo não recebeu financiamento.

Recebido em 6 de julho de 2020 Aprovado em 10 de dezembro de 2020 